\title{
High manganese exposure decreased the risk of high triglycerides in male workers: a cross-sectional study
}

xiaoyu luo

Guangxi Medical University zhenfang liu

Guangxi Medical University xiaoting ge

Guangxi Medical University

sifang huang

Guangxi Medical University

yanting zhou

Guangxi Medical University defu li

Guangxi Medical College

longman li

Anhui Medical University

xiang chen

Guangxi Medical University

lulu huang

Guangxi Medical University qingzhi hou

Guangxi Medical University hong cheng

Guangxi Medical University lili xiao

Guangxi Medical University chaoqun liu

Guangxi Medical University

yunfeng zou

Guangxi Medical University

Xiaobo Yang ( $\nabla$ yxbo21021@163.com )

Guangxi Medical University 


\section{Research article}

Keywords: Manganese; Occupation; Dyslipidemia; Triglycerides

Posted Date: November 11th, 2019

DOl: https://doi.org/10.21203/rs.2.17112/v1

License: (c) (i) This work is licensed under a Creative Commons Attribution 4.0 International License. Read Full License

Version of Record: A version of this preprint was published at BMC Public Health on June 5th, 2020. See the published version at https://doi.org/10.1186/s12889-020-09011-x. 


\section{Abstract}

Manganese $(\mathrm{Mn})$ is to be involved in lipids metabolism. However, few epidemiological studies have investigated the association between elevated exposure to $\mathrm{Mn}$ and the risk of dyslipidemia. Methods: This was a cross-sectional study based on follow-up of the manganese-exposed workers healthy cohort (MEWHC) in 2017. A total of 803 Mn-exposed workers were divided into the lowexposure, and high-exposure group according to Mn-Time Weighted Average (Mn-TWA) $\leq 0.15 \mathrm{mg} / \mathrm{m} 3$ or $>0.15 \mathrm{mg} / \mathrm{m3}$. And we evaluated the associations between Mn-TWA levels and dyslipidemia, and assessed the interaction between Mn-TWA levels and each of the potential interacting factors. Results: After adjustment for potential confounders, we observed mainly significant negative association between high triglycerides (TG) risk and Mn-TWA levels in male (OR $=0.60 ; 95 \% \mathrm{Cl}$ : 0.39, 0.94; $p$ <0.01). In interaction analyses of male, we did not observe a significant interaction between MnTWA levels and pack-years on high TG risk (relative excess risk for the interaction (RERI) $=-1.30,95 \% \mathrm{Cl}$ : $-3.29,0.70, \mathrm{RERI}=-1.62,95 \% \mathrm{Cl}$ : $-3.92,0.67)$. Similarly, analysis of smoking status, drinking status, highfat diets frequency, and BMI were nonsignificant interaction with Mn-TWA levels on high TG risk as well. Conclusions: Our study indicated that high Mn exposure was significantly associated with low risk of hyper TG in male workers.Keywords: Manganese; Occupation; Dyslipidemia; Triglycerides

\section{Background}

Manganese $(\mathrm{Mn})$ is an important trace element that plays an important role in immune system function, cell energy regulation, bone and connective tissue growth, blood coagulation, and reproductive hormones[1-3]. Meanwhile, excessive Mn has also been proved to have toxic effects on the human central nervous system, affecting specific areas of the central nervous system. Mn exposure in workers have been shown to induce neurotoxic effects resulting in neurobehavioral impairment and neuromotor deficits [4-7].

$\mathrm{Mn}$ has also been reported to be involved in lipids metabolism. However, the mechanism of effect of $\mathrm{Mn}$ on lipid metabolism is not clear for the time being. Some studies have reported that Mn reduced the total antioxidant status and increased brain lipids peroxidation in rats $[8,9]$. At the same time, $\mathrm{Mn}$ was found to stabilize lipoprotein particles in cell research and involved in the development of normal lipids composition and structure in rats $[10,11]$. Furthermore, Mn was found to enhance cholesterol biosynthesis in rats liver microsome and stimulate the activity of farnesyl pyrophosphate synthase. The important synthesis pathway for many lipids was the mevalonate pathway, and this enzyme was the first branch of this pathway [12-15]. However, studies on the effect of Mn on serum lipids were rare. A recent report found that rats exposed to low doses of Mn can reduce serum TG levels [16]. Meanwhile, epidemiological data were all focused on studies on dietary Mn intake. A dietary survey of Chinese people, $\mathrm{Mn}$ intake was negatively correlated with hypertriglyceridemia in male, while $\mathrm{Mn}$ was positively associated with low HDL-C only in female [17]. Similarly, in a study of obese men, high serum Mn was also found to significantly reduce HDL-C concentrations [18]. Another survey on polymetallic dietary intake in China found that Mn intake was negatively correlated with serum TG and T-CHO [19]. Welding, 
mining and smelting have long been considered occupations of manganese overexposure [20]. In addition, with the use of methyl cyclopentadienyl manganese tricarbonyl (MMT) as an antiknock agent in gasoline, the exposure of ordinary residents to manganese is also increasing[21]. The public health issues related to $\mathrm{Mn}$ are raising more and more concern in public health. However, no studies have assessed the relationship between Mn exposure and the changes in the levels of serum lipids in occupationally Mn-exposed workers.

Manganese-exposed workers healthy cohort (MEWHC) was a longitudinal prospective and multidisciplinary study that began in July to October 2011 in an iron and manganese smelters [22]. The primary goal of MEWHC was to explore early or long-term health effects, potential exposure biomarkers, and the diseases associated with $\mathrm{Mn}$ exposure. Therefore, we conducted this study to investigate $\mathrm{Mn}$ external exposure with dyslipidemia to explore the relationship between Mn exposure and serum lipids in occupationally Mn-exposed workers.

\section{Methods}

\section{Date collection}

This was a cross-sectional study based on follow-up of the manganese-exposed workers healthy cohort (MEWHC) in 2017, detailed description of the inclusion criteria and exclusion criteria for this cohort can be found in the previous study $[22,23]$. Face-to-face interviews were conducted by trained staff, and we used standardized and structured questionnaires to collect the basic information, including demographic information, smoking, drinking status, high-fat diets frequency, medicine intake in the past two weeks, and self-report chronic diseases. We measured height and weight, waist circumference, and blood pressure using standard methods. Body mass index $\left(\mathrm{BMl}, \mathrm{kg} / \mathrm{m}^{2}\right)$ was calculated from the height and weight measurements. The history of hypertension was defined according to the subjects' self-reported history and the results of blood pressure measured in the field, and the standard methods and definition of the Chinese guidelines for the prevention and treatment of hypertension to define hypertension (revised in 2018) was used[24]. We conducted a high animal fat diets frequency questionnaire to assess high fat diets intake. We divided the weekly high animal fat diets frequency into two groups, low high-fat diets frequency group was defined as the high-fat diets frequency less than 3 times per week, and high high-fat diets frequency group was defined as the high-fat diets frequency 3 times or more per week. Current smoking status was defined as smoking at least one cigarette per day for 6 consecutive months. Current drinker was defined as drinking more than $5 \mathrm{ml}$ at a time and drinking at least 3 times a week for 6 months. Participants were classified as nonsmoker, former smoker or current smoker. A pack-year was defined as 20 cigarettes smoked every day for one year [25]. We further categorized participants' smoking status into three groups on the basis of median pack-years: nonsmoker, $<18$ pack-years, and $\geq 18$ packyears.

Our study subjects were recruited from the follow-up of manganese-exposed workers healthy cohort (ME WHC) in 2017. According to the exclusion criteria, subjects with cancer, or coronary heart disease, or 
stroke disease, or diabetes were excluded from the 828 workers, as well as those whose biological samples were undetected. Finally, a total of twenty-two subjects were excluded from our study. In the end, a total of 803 occupationally Mn-exposed workers were invited to participate in our study. All biological samples include blood and urine samples were collected after a night of fasting, and immediately were transported to the biobank and stored deep frozen at $-80^{\circ} \mathrm{C}$ until be analyzed.

\section{Measurement of Mn concentration in the respirable dust}

We collected a total of 134 samples including 20 categories of relatively typical occupation by personal sampling. We selected three subjects in each occupation and measured their respiratory dust for 3 consecutive days. We used the air sampling pump (SENSIDYNE, GilAirPlus, US) and respirable dust sampling head (HXFC-WH, Wuhan, China), and glass fiber microporous filter membrane (diameter 0.22 $\mathrm{mm}, 37 \mathrm{~mm}$ diameter) to collect the respirable dust of the workers from the breathing zone of participants. Gas flow rates were set to $2 \mathrm{~L} / \mathrm{min}$ and flow rates checked both before and after the sampling, the average time we collected $6.9 \mathrm{~h}$ of sample per person per day. We tested only representative types of positions in the main workplace, individual exposure concentration of other positions was replaced by detected concentration with the same or similar workplace. We strictly abided by the national occupational health standard of the People's Republic of China. The standards are "Determination of airborne dust in the workplace part 2: Concentration of respirable dust" (GBZ/T 192.2-2007), and "Specifications of air sampling for hazardous substances monitoring in the workplace" (GBZ159-2004). The determine procedure followed the standard "Ambient air and stationary source emissionDetermination of metals in ambient particulate matter-Inductively Coupled Plasma Mass Spectrometry (ICP-MS)" (HJ657-2013).

Digestion of filter membrane: the filter membrane was placed in a Teflon tube and added with $10 \mathrm{ml}$ aqua regia. Microwave digestion instrument was used for digestion at 200 degrees Celsius for 30 minutes, diluted with ultrapure water to $50 \mathrm{ml}$ and measured by ICP-MS (Perkin Elmer, NexION 2000, USA). We used the isotope ${ }^{45} \mathrm{Sc}$ as the internal standard for the determination of Mn. Quality control (QC) measures included analysis of the initial calibration validation criteria, a repeat measurement for every 10 samples, and SRM1640A (natural trace element concentration in water). Mn metal had the limit of detection (LOD) of $0.076 \mu \mathrm{g} / \mathrm{L}$. All samples concentration was higher than the LOD. Finally, we calculated the timeweighted average of $\mathrm{Mn}$ (as $\mathrm{MnO}_{2}$ ) ( $\mathrm{Mn}$-TWA) based on the three day average concentration. According to the National occupational health standards of the People's Republic of China, the occupational exposure limits permissible concentration-time weighted average $\triangle \mathrm{PC}$-TWA囚for $\mathrm{Mn}$ and its compounds were set at $0.15 \mathrm{mg} / \mathrm{m}^{3}$ (as $\mathrm{MnO}_{2}$ ) based on an 8-hour time weighting.(GBZ 2.1-2007). Therefore, we divided all subjects into two groups, low-exposure group was defined as Mn-TWA $\leq 0.15 \mathrm{mg} / \mathrm{m}^{3}$ and highexposure was defined as $\mathrm{Mn}-\mathrm{TWA}>0.15 \mathrm{mg} / \mathrm{m}^{3}$. The high-exposure group mainly included smelters, welders, human crushing workers, casting crane workers, material crane workers. The low-exposure group mainly included circulating cooling water system operator, chemical analysts, office workers, security guards and workers in other auxiliary positions. 


\section{Measurement of Serum lipids}

Serum samples were stored in a deep freeze $-80^{\circ} \mathrm{C}$ until be tested. Serum lipids were measured by using chemistry automatic analyzer (Hitachi 7600-020, Kyoto, Japan) at the testing center of the Department of Clinical Laboratory at the First Affiliated Hospital of Guangxi Medical University in Nanning. Serum lipids include Total Cholesterol (T-CHO), Triglyceride (TG), Low-density lipoprotein cholesterol (LDL-C), and Highdensity lipoprotein cholesterol (HDL-C) [26]. Serum lipids were classified according to The 2016 Chinese Guideline for the Management of dyslipidemia in Adults (Chinese guideline). High LDL-C was defined as Low-density lipoprotein cholesterol $\geq 4.14 \mathrm{mmol} / \mathrm{L}$. high TG was defined as triglyceride $\geq 2.26 \mathrm{mmol} / \mathrm{L}$, high T-CHO was defined as total cholesterol $\geq 6.22 \mathrm{mmol} / \mathrm{L}$, and low HDL-C was defined as High-density lipoprotein cholesterol $<1.04 \mathrm{mmol} / \mathrm{L}$. Dyslipidemia was well-established with strong risk factors of cardiovascular diseases, and cardiovascular diseases are sequelae of dyslipidemia[27]. The dyslipidemia guideline suggested that a target of LDL-C should be set according to individual ASCVD risk, and the individual ASCVD risk was evaluated adjusted age, gender, BMI, history of hypertension, and smoking status[26].

\section{Statistical analysis}

Mann-Whitney $\mathrm{U}$ test was used to compare the lipids levels of low $\mathrm{Mn}$ exposure and high Mn exposure group. Logistic regression models was used to estimate Mn exposure levels and the adjusted odds ratio (ORs), 95\% confidence interval (Cls) of no achieving LDL-lowering targets risk, high LDL-C risk, high TG risk, high T-CHO risk, and low HDL-C risk, respectively. Specifically, because of the high inter variable correlation between age and seniority, the only seniority was adjusted in models. Finally, the potential confounders for models adjustment included gender, seniority, BMI, hypertension, medicine intake in the past two weeks, high-fat diets frequency, smoking status, and drinking status.

We conducted a stratified analysis according to strata of gender, seniority, BMI, hypertension, medicine intake in the past two weeks, high-fat diets frequency, smoking status, and drinking status. In our research, we considered the biologic interaction in potential risk factors. Rothman has argued that we should focus on epidemiological interaction or interaction on an additive scale by testing whether the joint effect from exposure to both factors was greater than the sum of their independent effects, and suggested the use of relative excess risk for interaction (RERI) in assessing additive interaction. The previous reports gave RERI a detailed explanation and calculation method [28-30]. Display quotations of over 40 words, or as needed. In short, RERI was calculated as follows:

$R E R I=e^{(\beta 1+\beta 2+\beta 3)}-e^{(\beta 1)}-e^{(\beta 2)}+1$

Where $\beta 1$ is the coefficient of the effect of Mn-TWA levels measure, $\beta 2$ is the coefficient of potential risk factor and $\beta 3$ is the coefficient of the cross-product of the Mn-TWA levels and potential risk factor. And we estimated $95 \%$ confidence intervals by using the standard delta method. When the relative excess risk for interaction is an estimate of more than zero, there is an additive scale interaction between the two risk factors, and the $95 \%$ confidence interval is positive and does not contain zero. RERI of 0 indicates exact 
additivity and there is no additive scale interaction. Finally, we assessed the interaction between Mn-TWA levels and each of the potential interacting factors of smoking effects (both smoking status and packyears), drinking status, high-fat food frequency, and BMI on high TG risk in the logistic regression models by using R software. Analyses were conducted using R (version 3.4) and SPSS (19.0), two-sided, $p<0.05$ was considered statistically significant.

\section{Results}

In our participants, the median seniority was 18.92 years old, and the median age for the low, and high exposure group were 41.75 years, 45.42 years, respectively. The median of seniority was 18.92 , and there was no difference in seniority between two groups $(p=0.07)$. Male made up the majority of the low, and high exposure groups at $57.6 \%$, and $72.5 \%$, respectively. Only male smokers in our study and the proportion of current smoker were higher in high exposure group compared with the low exposure group, and the rates was $26.2 \%, 10.6 \%$, respectively $(p<0.01)$. Similarly, the proportion of $\geq 18$ pack-years was higher in the high exposure group, and the rates was $29.4 \%, 14.5 \%$, respectively $(p<0.01)$. The current drinker account for a higher proportion of high-exposure group than that in the low-exposure group, and was $32.7 \%, 23.0 \%$, respectively $(p<0.01)$. In addition, the rates of $\mathrm{BMI} \geq 24.0 \mathrm{~kg} / \mathrm{m}^{2}$ in the low exposure group was higher than that in the high exposure group, and was $64.2 \%, 53.7 \%$, respectively $(p<0.01)$. However, hypertension and medicine intake in the past two weeks were not different in the two groups ( $p$ [ 0.05) (Table 1).

As shown in Table 2, the proportion of occupationally Mn-exposed workers with high TG ( $\geq 2.3 \mathrm{mmol} / \mathrm{L})$, high T-CHO ( $\geq 6.2 \mathrm{mmol} / \mathrm{L})$, high LDL-C ( $\geq 4.1 \mathrm{mmol} / \mathrm{L})$, and low HDL-C ( $<1.04 \mathrm{mmol} / \mathrm{L})$ was $25.5 \%, 15.7 \%$, $6.8 \%$, and $3.1 \%$, respectively. LDL-lowering targets were set according to individual ASCVD risk and prevalence rates was $27.3 \%$. The prevalence rates of high TG in low exposure group was higher than in the high exposure group, and was $30.7 \%, 22.7 \%$, respectively $(p<0.01)$.

In interaction analyses, we did not observe a significant additive scale interaction between Mn-TWA levels and smoking status, or pack-years on high TG risk (relative excess risk for the interaction (RERI) $=-1.68$, $95 \% \mathrm{Cl}:-3.76,0.40), \mathrm{RERI}=-0.78,95 \% \mathrm{Cl}:-2.59,1.04)$ for smoking status, RERI $=-1.30,95 \% \mathrm{Cl}:-3.29$, $0.70), \mathrm{RERI}=-1.62,95 \% \mathrm{Cl}:-3.92,0.67)$ for pack-years, respectively. Results of our study suggested that male in this cohort, the joint effect of with high level of Mn-TWA exposure and current smoking or former smoking was not greater than the sum of their individual effects, consistent results was found in $\geq 18$ pack-years or $<18$ pack-years. Similarly, we did not observe the significant interaction between Mn-TWA levels and drinking status, high-fat diets frequency, and BMI on high TG risk as well. Although not significant interaction, the risk of high TG seemed to be lower for people with a high level of Mn-TWA exposure who had high-fat diets frequency $\geq 3$ times/week (high) $(\mathrm{OR}=0.44 ; 95 \% \mathrm{Cl}: 0.24,0.79)(\mathrm{Table}$ 4).

\section{Discussion}


This is the first study to explore the relationship between Mn exposure and dyslipidemia in occupationally Mn-exposed workers. Our results showed that male workers exposed to higher Mn-TWA levels with lower high TG risk, and may no interaction with potential interaction factors. About the effect of $\mathrm{Mn}$ on lipids concentration, most studies have focused on dietary Mn intake. A clinical trial showed that after 14 adults supplemented with gluconic acid, $\mathrm{Mn}$ can reduce body fat by increasing fecal fat excretion [31]. Another clinical trial in seven young men, adequate intake of $\mathrm{Mn}$ can reduce plasma cholesterol levels[32]. A dietary study included 2111 Chinese adults has found a negative correlation between $\mathrm{Mn}$ intake and hypertriacylglycerolemia in male and Mn was positively correlated with low HDL-C concentration in female [17]. Another polymetallic dietary intake survey in 258 healthy male and female in China found that Mn intake was inversely correlated with serum TG and T-CHO [19]. In our population, the potential effect of gender was also observed. The negative correlation between Mn exposure and serum TG in male was consistent with previous findings. However, our study did not observe a correlation between Mn exposure and serum T-CHO, HDL-C, LDL-C, and LDL-lowering targets. Previous research results endorsed the important role of $\mathrm{Mn}$ in TG metabolism. However, it should be noted that our study subjects were occupational exposure to $\mathrm{Mn}$, thus dietary $\mathrm{Mn}$ intake concentration is not directly compared to occupational $\mathrm{Mn}$ exposure concentration in population. In order to explore how Mn involved in the regulation of lipids and the toxic dose on lipids, it is necessary to establish mammalian models that inhalation $\mathrm{Mn}$ exposure concentration is closer to the occupational exposure in the population.

$\mathrm{Mn}$ enters the bloodstream through intestinal absorption or olfactory channels. The liver plays a major role in the excretion of $\mathrm{Mn} . \mathrm{Mn}$ is absorbed into the liver from the blood and is regulated by homeostasis, excess $\mathrm{Mn}$ is mainly excreted into the intestine in combination with bile, finally, $\mathrm{Mn}$ in the liver complexes with different molecules and exists in the form of Mn2+[33-36]. At present, it was found previous studies provided biological support for the role of $\mathrm{Mn}$ in lipids metabolism. Some studies suggested that metabolism was thought to be related to lipids peroxidation [37-39]. Furthermore, another mechanism by which Mn may be involved in lipids metabolism was the process involved in lipids synthesis [12-15]. In summary, previous studies may suggest that Mn plays an important role in the mechanism of lipids. About lipid synthesis, there are two pathways for the synthesis of TG in the liver. One way is that exogenous fatty acids enter the liver cells and are esterified to synthesize TG, another pathway is produced by the de novo lipogenesis (DNL) pathway. Finally, the TG is placed in a storage pools or a secretory pool. The TG in storage pools is hydrolyzed by lipase, and the TG in the secretion pool is used for very low density lipoprotein (VLDL) assembly [40-43]. Acetyl-coa carboxylase is the key catalyst for the synthesis of de novo lipogenesis (DNL) acids. It requires a phosphatase to activate Acetyl-coa carboxylase, and the phosphatase's activation and dephosphorylation are dependent on Mn2+ [41, 44]. Thus, Mn2+ is an important coenzyme factor in liver synthesis of TG. In human and rodent studies, allosteric inhibition of acetyl-CoA carboxylase in the liver significantly reduced hepatic triglyceride levels, while plasma TG increased $[45,46]$. Studies have speculated that the degree of inhibition of acetyl-CoA carboxylase may ultimately determine the mechanism leading to hypertriglyceridemia in rodents and humans [47]. Our population exposed to higher Mn levels, we hypothesized that the Mn2+ stored in their liver may be higher. Therefore, acetyl-CoA carboxylase is more easily to be activated in the liver. 
Eventually, the level of triglyceride in the liver may be higher, while the level of triglycerides in serum drops.

Gender is a common factor affecting the absorption of $\mathrm{Mn}$ in individuals. Studies have reported that female have higher absorption rates of $\mathrm{Mn}$, and $\mathrm{Mn}$ levels in female's blood are significantly higher than male's [48-51]. However, Male are reported to be more prone to triglycerides, lipid abnormalities, and metabolic diseases [52-54]. We hypothesized that there may be differences in Mn-regulated lipid metabolism between male and female, as well as differences in estrogen and androgen levels, resulting in a decrease in the risk of high TG in male only with increased manganese exposure.

Our study is the first to explore the relationship between Mn exposure and dyslipidemia in occupational workers. We carefully measured and analyzed comprehensive information on risk factors and potential confounders associated with lipids metabolism to minimize the possibility of bias. In addition, the stability of the cohort will also provide long-term follow-up of participants in the future to assess the risks dyslipidemia with Mn exposure. Some limitations should be considered. First, the present study did not select a non-Mn exposed population as a control group. Thus, regional diet and genetic and environmental influences cannot be eliminated, which may lead to biased results. Secondly, due to the reform of the job type of our participants, the measurement data cannot accurately calculate $\mathrm{Mn}$ cumulative exposure index (Mn-CEI), which makes it impossible to deeply explore the relationship between the cumulative exposure dose of long-term $\mathrm{Mn}$ and dyslipidemia.

\section{Conclusions}

In summary, we found a good negative correlation between high TG and Mn exposure levels in male workers, and more epidemiological studies are needed to determine the relationship between $\mathrm{Mn}$ exposure and dyslipidemia in the population.

\section{Abbreviations}

MMT: methyl cyclopentadienyl manganese tricarbonyl; TWA: Time-weighted Average; TG: Triglycerides; TCHO; Total Cholesterol; LDL-C: Low-density lipoprotein cholesterol, HDL-C: High-density lipoprotein cholesterol;BMI: Body Mass Index; RERI: relative excess risk for the interaction; ICP-MS: Inductively Coupled Plasma Mass Spectrometry; MEWHC: Manganese-exposed Workers Healthy Cohort; QC: Quality control; PC-TWA: permissible concentration-time weighted average; LOD: limit of detection; DNL: de novo lipogenesis; VLDL: Low density lipoprotein; Mn-CEl: cumulative exposure index;

\section{Declarations}

\section{Acknowledgements}

We thank all study participants and researchers of the MEWHC study. And all authors make significant contributions to this article. 


\section{Declarations}

\section{Authors' contributions}

XBY contributed to conception and design; SFH, YTZ, DFL, LML, XC, LLH, HC, QZH, LLX, CQL and YFZ contributed to acquisition of the data; XYL, ZFL, XTG and analyzed the data and drafted the manuscript. LXY, ZFL and XTG contributed equally to this study. All authors approved the final manuscript of this article prior to submission.

\section{Funding}

This research was funded by the National Natural Science Foundation of China [grant number 81860573] and Guangxi Natural Science Fund for Innovation Research Team [grant number 2017GXNSFGA198003].

\section{Availability of data and materials}

The data and material are available upon reasonable request from the corresponding author. E-mail: yxbo21021@163.com.

\section{Ethics approval and consent to participate}

The Medical Ethics Committee of Guangxi Medical University approved this study. All participants were fully informed about the study purpose and methods and provided written consent to participate.

\section{Consent for publication}

Not Applicable.

\section{Competing interests}

The authors declare that they have no competing interest.

\section{Author details}

${ }^{1}$ Department of Occupational Health and Environmental Health, School of Public Health, Guangxi Medical University, Nanning, Guangxi, China

${ }^{2}$ Department of Hematology, The First Affiliated Hospital of Guangxi Medical University, Nanning, Guangxi, China

${ }^{3}$ Department of Nutrition and Food Hygiene, School of Public Health, Guangxi Medical University, Nanning, Guangxi, China

${ }^{4}$ Department of Toxicology, School of Public Health, Guangxi Medical University, Nanning, Guangxi, China 
${ }^{5}$ Guangxi Colleges and Universities Key Laboratory of Prevention and Control of Highly Prevalent Diseases, Guangxi Medical University, Nanning, Guangxi, China

${ }^{6}$ Center for Genomic and Personalized Medicine, Guangxi Medical University, Nanning, Guangxi, China

\section{References}

1. Takeda A: Manganese action in brain function. Brain research Brain research reviews 2003, 41(1):7987.

2. Aschner $\mathrm{JL}$, Aschner M: Nutritional aspects of manganese homeostasis. Molecular aspects of medicine 2005, 26(4-5):353-362.

3. Mertz W: The essential trace elements. Science 1981, 213(4514):1332-1338.

4. Crossgrove J, Zheng W: Manganese toxicity upon overexposure. NMR in biomedicine 2004, 17(8):544-553.

5. Guilarte TR: Manganese and Parkinson's disease: a critical review and new findings. Environmental health perspectives 2010, 118(8):1071-1080.

6. Santamaria AB, Sulsky SI: Risk assessment of an essential element: manganese. Journal of toxicology and environmental health Part A 2010, 73(2):128-155.

7. Aschner M, Guilarte TR, Schneider JS, Zheng W: Manganese: Recent advances in understanding its transport and neurotoxicity. Toxicology and Applied Pharmacology 2007, 221(2):131-147.

8. Ganeshan M, Sainath PB, Padmavathi IJ, Venu L, Kishore YD, Kumar KA, Harishanker N, Rao JS, Raghunath $M$ : Maternal manganese restriction increases susceptibility to high-fat diet-induced dyslipidemia and altered adipose function in WNIN male rat offspring. Experimental diabetes research 2011, 2011:486316.

9. Malhotra KM, Murthy RC, Srivastava RS, Chandra SV: Concurrent exposure of lead and manganese to iron-deficient rats: effect on lipid peroxidation and contents of some metals in the brain. Journal of applied toxicology: JAT 1984, 4(1):22-25.

10. Bell LT, Hurley LS: Ultrastructural effects of manganese deficiency in liver, heart, kidney, and pancreas of mice. Laboratory investigation; a journal of technical methods and pathology 1973, 29(6):732736 .

11. Robberecht HJ, Hendrix P, Van Cauwenbergh R, Deelstra HA: Daily dietary manganese intake in Belgium, using duplicate portion sampling. Zeitschrift fur Lebensmittel-Untersuchung und Forschung 1994, 199(6):446-448.

12. McTaggart SJ: Isoprenylated proteins. Cellular and molecular life sciences : CMLS2006, 63(3):255267.

13. Curran GL, Azarnoff DL: Effect of certain transition elements on cholesterol biosynthesis. Federation proceedings 1961, 20(3)Pt 2:109-111. 
14. Curran GL: Effect of certain transition group elements on hepatic synthesis of cholesterol in the rat. The Journal of biological chemistry 1954, 210(2):765-770.

15. Park J, Zielinski M, Magder A, Tsantrizos YS, Berghuis AM: Human farnesyl pyrophosphate synthase is allosterically inhibited by its own product. Nature communications 2017, 8:14132.

16. Oladipo 00, Ayo JO, Ambali SF, Mohammed B, Aluwong T: Dyslipdemia induced by chronic low dose co-exposure to lead, cadmium and manganese in rats: the role of oxidative stress. Environmental toxicology and pharmacology 2017, 53:199-205.

17. Zhou B, Su X, Su D, Zeng F, Wang MH, Huang L, Huang E, Zhu Y, Zhao D, He D et al: Dietary intake of manganese and the risk of the metabolic syndrome in a Chinese population. The British journal of nutrition 2016, 116(5):853-863.

18. Rotter I, Kosik-Bogacka D, Dolegowska B, Safranow K, Lubkowska A, Laszczynska M: Relationship between the concentrations of heavy metals and bioelements in aging men with metabolic syndrome. International journal of environmental research and public health 2015, 12(4):3944-3961.

19. Kim M-H, Choi M-K: Seven Dietary Minerals (Ca, P, Mg, Fe, Zn, Cu, and Mn) and Their Relationship with Blood Pressure and Blood Lipids in Healthy Adults with Self-Selected Diet. Biological trace element research 2013, 153(1-3):69-75.

20. Gerber GB, Leonard A, Hantson P: Carcinogenicity, mutagenicity and teratogenicity of manganese compounds. Critical reviews in oncology/hematology 2002, 42(1):25-34.

21. Joselow MM, Tobias E, Koehler R, Coleman S, Bogden J, Gause D: Manganese pollution in the city environment and its relationship to traffic density. American journal of public health 1978, 68(6):557560 .

22. Lv Y, Zou Y, Liu J, Chen K, Huang D, Shen Y, Zhong Y, Liu Z, Jiang B, Li Q et al: Rationale, design and baseline results of the Guangxi manganeseexposed workers healthy cohort (GXMEWHC) study. $B M J$ open 2014, 4(7):e005070.

23. Zhou Y, Ge X, Shen Y, Qin L, Zhong Y, Jiang C, Su C, Huang J, Lin S, Li D et al: Follow-up of the manganese exposed workers healthy cohort (MEWHC) and biobank management from 2011 to 2017 in China. BMC public health 2018, 18(1):944.

24. Hypertension alliance (China) ea: Chinese guidelines for the prevention and treatment of hypertension (2018 revision). Chinese journal of cardiovascular medicine 2019, 24(1):25.

25. Bernaards CM, Twisk JW, Snel J, Van Mechelen W, Kemper HC: Is calculating pack-years retrospectively a valid method to estimate life-time tobacco smoking? A comparison between prospectively calculated pack-years and retrospectively calculated pack-years. Addiction 2001, 96(11):1653-1661.

26. Junren zhu RG, Shuiping Zhao, Guoping Lu, Dong Zhao, Jianjun Li.: 2016 Chinese guidelines for the management of dyslipidemia in adults. Journal of geriatric cardiology : JGC 2018, 15(1):1-29.

27. Stone NJ, Robinson JG, Lichtenstein AH, Bairey Merz CN, Blum CB, Eckel RH, Goldberg AC, Gordon D, Levy D, Lloyd-Jones DM et al: 2013 ACC/AHA guideline on the treatment of blood cholesterol to reduce atherosclerotic cardiovascular risk in adults: a report of the American College of 
Cardiology/American Heart Association Task Force on Practice Guidelines. Circulation 2014, 129(25 Suppl 2):S1-45.

28. Chen Y, Graziano JH, Parvez F, Liu M, Slavkovich V, Kalra T, Argos M, Islam T, Ahmed A, RakibuzZaman $\mathrm{M}$ et al: Arsenic exposure from drinking water and mortality from cardiovascular disease in Bangladesh: prospective cohort study. Bmj 2011, 342:d2431.

29. Knol MJ, van der Tweel I, Grobbee DE, Numans ME, Geerlings MI: Estimating interaction on an additive scale between continuous determinants in a logistic regression model. International journal of epidemiology 2007, 36(5):1111-1118.

30. Li R, Chambless L: Test for additive interaction in proportional hazards models. Annals of epidemiology 2007, 17(3):227-236.

31. Potter SM, Kies CV, Rojhani A: Protein and fat utilization by humans as affected by calcium phosphate, calcium carbonate, and manganese gluconate supplements. Nutrition 1990, 6(4):309312.

32. Friedman BJ, Freeland-Graves JH, Bales CW, Behmardi F, Shorey-Kutschke RL, Willis RA, Crosby JB, Trickett PC, Houston SD: Manganese balance and clinical observations in young men fed a manganese-deficient diet. The Journal of nutrition 1987, 117(1):133-143.

33. Kim J, Buckett PD, Wessling-Resnick M: Absorption of manganese and iron in a mouse model of hemochromatosis. PloS one 2013, 8(5):e64944.

34. Brenneman KA, Wong BA, Buccellato MA, Costa ER, Gross EA, Dorman DC: Direct olfactory transport of inhaled manganese $((54) \mathrm{MnCl}(2))$ to the rat brain: toxicokinetic investigations in a unilateral nasal occlusion model. Toxicol Appl Pharmacol 2000, 169(3):238-248.

35. Hauser RA, Zesiewicz TA, Rosemurgy AS, Martinez C, Olanow CW: Manganese intoxication and chronic liver failure. Annals of neurology 1994, 36(6):871-875.

36. Zeron HM, Rodriguez MR, Montes S, Castaneda CR: Blood manganese levels in patients with hepatic encephalopathy. Journal of trace elements in medicine and biology : organ of the Society for Minerals and Trace Elements 2011, 25(4):225-229.

37. Ismail HTH: Hematobiochemical Disturbances and Oxidative Stress After Subacute Manganese Chloride Exposure and Potential Protective Effects of Ebselen in Rats. Biological trace element research 2019, 187(2):452-463.

38. Porter NA, Caldwell SE, Mills KA: Mechanisms of free radical oxidation of unsaturated lipids. Lipids 1995, 30(4):277-290.

39. Gutteridge JM, Halliwell B: The measurement and mechanism of lipid peroxidation in biological systems. Trends in biochemical sciences 1990, 15(4):129-135.

40. Olofsson SO, Boren J: Apolipoprotein B: a clinically important apolipoprotein which assembles atherogenic lipoproteins and promotes the development of atherosclerosis. Journal of internal medicine 2005, 258(5):395-410.

41. Sahini N, Borlak J: Recent insights into the molecular pathophysiology of lipid droplet formation in hepatocytes. Progress in lipid research 2014, 54:86-112. 
42. Trickett JI, Patel DD, Knight BL, Saggerson ED, Gibbons GF, Pease RJ: Characterization of the rodent genes for arylacetamide deacetylase, a putative microsomal lipase, and evidence for transcriptional regulation. The Journal of biological chemistry 2001, 276(43):39522-39532.

43. Zammit Victor A: Hepatic triacylglycerol synthesis and secretion: DGAT2 as the link between glycaemia and triglyceridaemia. Biochemical Journal 2013, 451(1):1-12.

44. Thampy KG, Wakil SJ: Activation of acetyl-CoA carboxylase. Purification and properties of a Mn2+dependent phosphatase. The Journal of biological chemistry 1985, 260(10):6318-6323.

45. Abu-Elheiga L, Matzuk MM, Abo-Hashema KA, Wakil SJ: Continuous fatty acid oxidation and reduced fat storage in mice lacking acetyl-CoA carboxylase 2. Science 2001, 291(5513):2613-2616.

46. Kim CW, Addy C, Kusunoki J, Anderson NN, Deja S, Fu X, Burgess SC, Li C, Ruddy M, Chakravarthy M et al: Acetyl CoA Carboxylase Inhibition Reduces Hepatic Steatosis but Elevates Plasma Triglycerides in Mice and Humans: A Bedside to Bench Investigation. Cell metabolism 2017, 26(3):576.

47. Abu-Elheiga L, Oh W, Kordari P, Wakil SJ: Acetyl-CoA carboxylase 2 mutant mice are protected against obesity and diabetes induced by high-fat/high-carbohydrate diets. Proceedings of the National Academy of Sciences of the United States of America 2003, 100(18):10207-10212.

48. Bocca B, Madeddu R, Asara Y, Tolu P, Marchal JA, Forte G: Assessment of reference ranges for blood $\mathrm{Cu}, \mathrm{Mn}, \mathrm{Se}$ and $\mathrm{Zn}$ in a selected Italian population. Journal of trace elements in medicine and biology : organ of the Society for Minerals and Trace Elements 2011, 25(1):19-26.

49. Clark NA, Teschke K, Rideout K, Copes R: Trace element levels in adults from the west coast of Canada and associations with age, gender, diet, activities, and levels of other trace elements. Chemosphere 2007, 70(1):155-164.

50. Lee JW, Lee CK, Moon CS, Choi IJ, Lee KJ, Yi SM, Jang BK, Yoon BJ, Kim DS, Peak D et al: Korea National Survey for Environmental Pollutants in the Human Body 2008: heavy metals in the blood or urine of the Korean population. International journal of hygiene and environmental health 2012, 215(4):449-457.

51. Zhang LL, Lu L, Pan YJ, Ding CG, Xu DY, Huang CF, Pan XF, Zheng W: Baseline blood levels of manganese, lead, cadmium, copper, and zinc in residents of Beijing suburb. Environmental research 2015, 140:10-17.

52. Mihailidou AS, Ashton AW: Cardiac effects of aldosterone: does gender matter? Steroids 2014, 91:3237.

53. Zhang X, Meng Z, Li X, Liu M, Ren X, Zhu M, He Q, Zhang Q, Song K, Jia Q et al: The association between total bilirubin and serum triglyceride in both sexes in Chinese. Lipids in health and disease 2018, 17(1):217.

54. Onat $A$, Karadeniz $Y$, Tusun $E$, Yuksel $H$, Kaya $A$ : Advances in understanding gender difference in cardiometabolic disease risk. Expert review of cardiovascular therapy 2016, 14(4):513-523.

55. Bhowmik B, Munir SB, Diep LM, Siddiquee T, Habib SH, Samad MA, Azad Khan AK, Hussain A: Anthropometric indicators of obesity for identifying cardiometabolic risk factors in a rural Bangladeshi population. Journal of diabetes investigation 2013, 4(4):361-368. 
56. Chehrei A, Sadrnia S, Keshteli AH, Daneshmand MA, Rezaei J: Correlation of dyslipidemia with waist to height ratio, waist circumference, and body mass index in Iranian adults. Asia Pacific journal of clinical nutrition 2007, 16(2):248-253.

57. Mota dos Santos C, Sa Silva C, Cesar de Araujo E, Kruze Grande de Arruda I, da Silva Diniz A, Coelho Cabral P: [Lipid and glucose profiles in outpatients and their correlation with anthropometric indices]. Revista portuguesa de cardiologia : orgao oficial da Sociedade Portuguesa de Cardiologia = Portuguese journal of cardiology : an official journal of the Portuguese Society of Cardiology 2013, 32(1):35-41.

58. Bibiloni MM, Salas R, Pons A, Tur JA: Prevalence of dyslipidaemia and associated risk factors among Balearic Islands adolescents, a Mediterranean region. European journal of clinical nutrition 2015, 69(6):722-728.

59. Wang L, Xu F, Zhang XJ, Jin RM, Li X: Effect of high-fat diet on cholesterol metabolism in rats and its

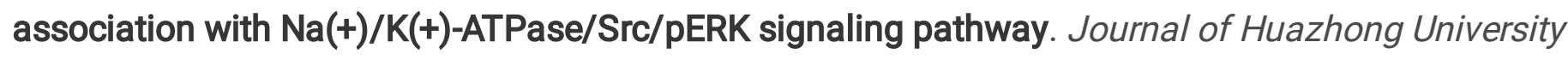
of Science and Technology Medical sciences = Hua zhong ke ji da xue xue bao Yi xue Ying De wen ban = Huazhong keji daxue xuebao Yixue Yingdewen ban 2015, 35(4):490-494.

\section{Tables}

Table 1 Demographic characteristics of the manganese-exposed workers from MEHWC. 


\begin{tabular}{|c|c|c|c|c|}
\hline Variables & Total $(\mathrm{n}=803)$ & $\begin{array}{l}\text { Low exposure } \\
\text { group }(n=283)\end{array}$ & $\begin{array}{l}\text { High exposure } \\
\text { group }(n=520)\end{array}$ & $\begin{array}{l}p \quad- \\
\text { Value* }\end{array}$ \\
\hline Age (years) & $44.25(39.50,48.42)$ & $41.75(36.58,46.92)$ & $45.42(41.27,49.08)$ & $<0.01$ \\
\hline Seniority (years) & & & & 0.07 \\
\hline$<18.92$ & $402(50.1)$ & $154(54.4)$ & $248(47.7)$ & \\
\hline$\geq 18.92$ & $401(49.9)$ & $129(45.6)$ & $272(52.3)$ & \\
\hline BMI $\left(\mathrm{kg} / \mathrm{m}^{2}\right)$ & & & & $<0.01$ \\
\hline$<24$ & $317(39.5)$ & $131(46.3)$ & $186(35.8)$ & \\
\hline$\geq 24$ & $486(60.5)$ & $152(53.7)$ & $334(64.2)$ & \\
\hline Gender & & & & $<0.01$ \\
\hline Male & $540(67.2)$ & $163(57.6)$ & $377(72.5)$ & \\
\hline Female & $263(32.8)$ & $120(42.4)$ & $143(27.5)$ & \\
\hline Race & & & & 0.65 \\
\hline Han & $361(45.0)$ & $128(45.2)$ & $233(44.8)$ & \\
\hline Zhuang & $409(50.9)$ & $141(49.8)$ & $268(51.5)$ & \\
\hline Other race & $33(4.1)$ & $14(4.9)$ & $19(3.7)$ & \\
\hline Education level & & & & $<0.01$ \\
\hline Middle school & $257(32.0)$ & $39(13.8)$ & $218(41.9)$ & \\
\hline or below & & & & \\
\hline High school & $367(45.7)$ & $103(36.4)$ & $264(50.8)$ & \\
\hline Junior college & $179(22.3)$ & $141(49.8)$ & $38(7.3)$ & \\
\hline or above & & & & \\
\hline Smoking status & & & & $<0.01$ \\
\hline Nonsmoker & $476(59.3)$ & $208(73.5)$ & $268(51.5)$ & \\
\hline Former smoker & $161(20.0)$ & $45(15.9)$ & $116(22.3)$ & \\
\hline Current smoker & 166(20.7) & $30(10.6)$ & $136(26.2)$ & \\
\hline Pack-years ${ }^{b}$ & & & & $<0.01$ \\
\hline Nonsmoker & $431(53.7)$ & $193(68.2)$ & $238(45.8)$ & \\
\hline$<18$ years (low) & $178(22.2)$ & $49(17.3)$ & $129(24.8)$ & \\
\hline
\end{tabular}



$\geq 18$ years
194(24.1)
41(14.5)
153(29.4)

(high)

Drinking status

$<0.01$

Former/never 568(70.7)

218(77.0)

$350(67.3)$

drinker

Current drinker 235(29.3)

65(23.0)

170(32.7)

High-fat diets

$<0.01$

frequency

<3times/week 640(79.7)

242(85.5)

398(76.5)

$\geq 3$ times/week 163(20.3)

41(14.5)

122(23.5)

Hypertension

Yes

251(31.3)

81(28.6)

170(32.7)

No

$552(68.7)$

202(71.4)

$350(67.3)$

Medicine intake in the past two weeks

0.85

Yes

283(35.2)

69(34.7)

214(35.4)

No

$520(64.8)$

130(65.3)

390(64.6)

Mn-TWA, Mn-Time Weighted Average; Low exposure group, Mn-TWA $\leq 0.15 \mathrm{mg} / \mathrm{m}^{3}$; High exposure group, MnTWA $>0.15 \mathrm{mg} / \mathrm{m}^{3}$; MEHWC, Manganese-exposed workers healthy cohort; BMI, Body Mass Index; Data were presented as median (25th, 75th) or $\mathrm{n}(\%)$.

$x_{p}$-Value were derived from Mann-Whitney $\mathrm{U}$ tests for continuous variables according to the data distribution, and chi-square test for the categorical variables.

**pack-years: A pack-year was defined as 20 cigarettes smoked every day for 1 year (Bernaards et al. 2001). We further categorized participants' smoking status into three groups on the basis of median pack-years: nonsmoker, $<18$ pack-years, and $\geq 18$ pack-years.

Table 2 Prevalence of different forms of dyslipidemia among participants from MEHWC. 


\begin{tabular}{|c|c|c|c|c|}
\hline Variables & $\operatorname{Total}(\mathrm{n}=803)$ & $\begin{array}{l}\text { Low exposure } \\
\text { group }(\mathrm{n}=283)\end{array}$ & $\begin{array}{l}\text { High exposure } \\
\text { group }(n=520)\end{array}$ & $\begin{array}{l}p \quad- \\
\text { Value* }\end{array}$ \\
\hline Triglycerides & & & & 0.01 \\
\hline$\geq 2.3 \mathrm{mmol} / \mathrm{L}$ & $205(25.5)$ & $87(30.7)$ & $118(22.7)$ & \\
\hline$<2.3 \mathrm{mmol} / \mathrm{L}$ & $598(74.5)$ & 196(69.3) & $402(77.3)$ & \\
\hline Total & & & & 0.18 \\
\hline \multicolumn{5}{|l|}{ cholesterol } \\
\hline$\geq 6.2 \mathrm{mmol} / \mathrm{L}$ & $126(15.7)$ & $51(18.0)$ & $75(14.4)$ & \\
\hline$<6.2 \mathrm{mmol} / \mathrm{L}$ & $677(84.3)$ & $232(82.0)$ & $445(85.6)$ & \\
\hline LDL-C & & & & 0.44 \\
\hline$\geq 4.1 \mathrm{mmol} / \mathrm{L}$ & $55(6.8)$ & $22(7.8)$ & $33(6.3)$ & \\
\hline$<4.1 \mathrm{mmol} / \mathrm{L}$ & $748(93.2)$ & $261(92.2)$ & $487(93.7)$ & \\
\hline HDL-C & & & & 0.61 \\
\hline$<1.0 \mathrm{mmol} / \mathrm{L}$ & $25(3.1)$ & $10(3.5)$ & $15(2.9)$ & \\
\hline$\geq 1.0 \mathrm{mmol} / \mathrm{L}$ & 778(96.9) & $273(96.5)$ & $505(97.1)$ & \\
\hline $\begin{array}{l}\text { No achieving } \\
\text { targets }\end{array}$ & LDL-lowering & & & 0.57 \\
\hline Yes & $220(27.4)$ & $81(28.6)$ & $139(26.7)$ & \\
\hline No & $583(72.6)$ & $202(71.4)$ & $381(73.3)$ & \\
\hline
\end{tabular}

Mn-TWA, Mn-Time Weighted Average; Low exposure group, Mn-TWA $\leq 0.15 \mathrm{mg} / \mathrm{m}^{3}$; High exposure group, MnTWA $>0.15 \mathrm{mg} / \mathrm{m}^{3}$; LDL-C, Low-density lipoprotein cholesterol. HDL-C, High-density lipoprotein cholesterol; MEHWC, Manganese-exposed workers healthy cohort; No achieving LDL-lowering targets, According to the Chinese guideline-2016 Chinese Guideline for the Management of Dyslipidemia in Adults[26], LDL-lowering targets were set according to individual ASCVD risk levels. Adjusted by age, gender, BMI, history of hypertension, and smoking status.

${ }^{*} p$-Value were derived from chi-square test. 
Table 3 Adjusted odds ratios [95\% confidence interval (CI)] for different forms of dyslipidemia according to Mn-TWA levels in MEHWC.

\begin{tabular}{|c|c|c|c|c|c|}
\hline \multirow[t]{3}{*}{ Dyslipidemia } & & \multicolumn{2}{|l|}{ Model $1^{*}$} & \multicolumn{2}{|l|}{ Model $2^{* *}$} \\
\hline & & OR(95\% CI) & $p$ & OR(95\% CI) & \\
\hline & & & Value & & Value \\
\hline $\begin{array}{l}\text { No achieving } \\
\text { targets }\end{array}$ & LDL-lowering & $0.91(0.66,1.26)$ & 0.48 & $0.86(0.62,1.20)$ & 0.37 \\
\hline High LDL-C & & $0.80(0.46,1.41)$ & 0.80 & $0.70(0.39,1.28)$ & 0.25 \\
\hline High TG & & $0.66(0.48,0.92)$ & 0.01 & $0.59(0.41,0.84)$ & $<0.01$ \\
\hline High T-CHO & & $0.77(0.52,1.13)$ & 0.18 & $0.75(0.50,1.14)$ & 0.18 \\
\hline Low HDL-C & & $0.81(0.36,1.83)$ & 0.61 & $0.73(0.30,1.76)$ & 0.49 \\
\hline
\end{tabular}

Logistic regression models was used for analysis, with different forms of dyslipidemia as the dependent variable and Mn-TWA levels (categorical variable) as the independent variable. No achieving LDL-lowering targets, low-density lipoprotein cholesterol targets were set according to individual ASCVD risk, and adjusted for the variables as drug status in the past two weeks, and alcohol intake status. According to the Chinese guideline-2016 Chinese Guideline for the Management of Dyslipidemia in Adults[26], high LDL-C was defined as Low-density lipoprotein cholesterol $\geq 4.14 \mathrm{mmol} / \mathrm{L}$, high TG was defined as triglycerides $\geq 2.3 \mathrm{mmol} / \mathrm{L}$, high T$\mathrm{CHO}$ was defined as total cholesterol $\geq 6.2 \mathrm{mmol} / \mathrm{L}$, and low HDL-C was defined as High-density lipoprotein cholesterol $<1.0 \mathrm{mmol} / \mathrm{L}$.

*Model 1: Without adjusting covariates.

${ }^{* \star}$ Model 2: Adjusted for the variables as gender, seniority, BMI, hypertension, medicine intake in the past two weeks, high-fat diets frequency, smoking status, and drinking status.

Table 4 Adjusted odds ratios [95\% confidence interval (CI)] for high TG according to the combined exposure Mn-TWA levels with categories of smoking status, pack-years, drinking status High-fat diets, and BMI in male workers. 


\begin{tabular}{lllll}
\hline Variables & n(high & Low exposure & High exposure & Relative excess risk due \\
& /normal & & & to interaction(RERI $)^{* *}$ \\
\cline { 3 - 4 } & TG) & OR $^{*}(95 \% \mathrm{CI})$ & $\mathrm{OR}^{*}(95 \% \mathrm{CI})$ & $(95 \% \mathrm{CI})$ \\
\hline
\end{tabular}

Smoking

status

Nonsmoker $\quad 88 / 343 \quad 1.00 \quad 1.09(0.53,2.26)$

Former $11 / 34 \quad 1.31(0.39,4.34) \quad 0.55(0.18,1.69) \quad-1.68(-3.76,0.40)$

smoker

Current $106 / 221 \quad 2.80(1.35,5.81) \quad 1.19(0.64,2.24) \quad-0.78(-2.59,1.04)$

smoker

Pack years ${ }^{\mathrm{c}}$

Nonsmoker $\quad 88 / 343 \quad 1.00 \quad 1.09(0.53,2.25)$

$<18$ years $56 / 122 \quad 2.27(1.01,5.11) \quad 1.15(0.58,2.28) \quad-1.30(-3.29,0.70)$

(low)

$\geq 18$ years $61 / 133 \quad 2.63(1.14,6.09) \quad 1.06(0.54,2.08) \quad-1.62(-3.92,0.67)$

(high)

Drinking

$-0.46(-1.55,0.62)$

status

Former/never $127 / 441 \quad 1.00 \quad 0.68(0.39,1.19)$

drinker

$$
\text { Current } 78 / 157 \quad 1.52(0.77,3.01) \quad 0.75(0.41,1.36)
$$

drinker

High-fat diets

frequency

$$
<3 \quad 165 / 475 \quad 1.00 \quad 0.48(0.30,0.77)
$$

times/week

(low)

$$
\geq 3 \quad 40 / 123 \quad 0.24(0.07,0.76) \quad 0.44(0.24,0.79)
$$

times/week 
(high)

BMI

$\begin{array}{lll}\text { BMI } 90 / 396 & 1.00 & 0.50(0.27,0.95)\end{array}$

$<24 \mathrm{~kg} / \mathrm{m}^{2}$

BMI $115 / 202 \quad 2.01(1.02,3.97) \quad 1.34(0.72,2.51)$

$\geq 24 \mathrm{~kg} / \mathrm{m}^{2}$

Low exposure group, Mn-TWA $\leq 0.15 \mathrm{mg} / \mathrm{m}^{3}$; High exposure group, Mn-TWA $>0.15 \mathrm{mg} / \mathrm{m}^{3}$. pack-years, A packyear was defined as 20 cigarettes smoked every day for 1 year[25]. We further categorized participants' smoking status into three groups on the basis of median pack-years: nonsmoker, $<18$ pack-years, and $\geq 18$ pack-years.

*OR: In our cohort, only participants were male, Mn-TWA levels showed stronger negative associations with high TG risk. And OR across the combined exposure of Mn-TWA levels and the other risks factors of dyslipidemia were obtained in logistic regression models in male. Adjusted for the variables as gender, seniority, smoking status, pack-years, drinking status, hypertension, medicine status in the past two weeks, and BMI; Combined categories variables did not be adjusted.

${ }^{* *}$ RERI: We assessed the presence of interaction between exposure Mn-TWA levels and smoking status, packyears, drinking status, High-fat diets, and BMI by testing whether the joint effect from exposure to both factors was greater than the sum of their independent effects. When the relative excess risk for interaction is an estimate of more than zero, there is an additive scale interaction between the two risk factors, and the $95 \%$ confidence interval is positive and does not contain zero. Otherwise, there was no interaction, and RERI of 0 indicates exact additivity and there is no additive scale interaction.

\section{Figures}




\begin{tabular}{|c|c|c|c|}
\hline Subgroup & & & odds ratios $(95 \% \mathrm{Cl})$ \\
\hline Overall & $205 / 598$ & $\mapsto$ & $0.59(0.41,0.84)$ \\
\hline Gender & & & \\
\hline Male & $160 / 380$ & & $0.60(0.39,0.94)$ \\
\hline Female & $45 / 218$ & & $0.59(0.30,1.16)$ \\
\hline Seniority & & & \\
\hline$<18.92$ years & $88 / 314$ & $\longmapsto$ & $0.47(0.28,0.79)$ \\
\hline$\geq 18.92$ years & $117 / 284$ & & $0.75(0.44,1.28)$ \\
\hline Smoking status & & & \\
\hline Nonsmoker & $88 / 343$ & & $0.77(0.47,1.25)$ \\
\hline Former smoker & $11 / 34$ & & $0.35(0.07,1.85)$ \\
\hline Current smoker & $106 / 221$ & - & $0.44(0.25,0.78)$ \\
\hline Pack-years & & & \\
\hline Nonsmoker & $88 / 343$ & & $0.77(0.47,1.25)$ \\
\hline$<18$ years(low) & $56 / 122$ & & $0.49(0.24,1.00)$ \\
\hline$\geq 18$ years (high) & $61 / 133$ & & $0.42(0.20,0.90)$ \\
\hline $\mathrm{BMI}$ & & & \\
\hline $\mathrm{BMI}<24 \mathrm{~kg} / \mathrm{m}^{2}$ & $90 / 396$ & $\curvearrowleft$ & $0.46(0.27,0.79)$ \\
\hline $\mathrm{BMI} \geq 24 \mathrm{~kg} / \mathrm{m}^{2}$ & $115 / 202$ & & $0.72(0.43,1.22)$ \\
\hline High-fat diet frequency & & & \\
\hline$<3$ times/week(low) & $165 / 475$ & $\mapsto$ & $0.53(0.35,0.80)$ \\
\hline$\geq 3$ times /week(high) & $40 / 123$ & & $1.04(0.42,2.59)$ \\
\hline Drinking status & & & \\
\hline Former/never drinker & $127 / 441$ & & $0.64(0.41,0.99)$ \\
\hline Current drinker & $78 / 157$ & & $0.54(0.28,1.06)$ \\
\hline Hypertension & & & \\
\hline History of hypertension & $140 / 412$ & & $0.81(0.40,1.63)$ \\
\hline No hypertension & $65 / 186$ & $\mapsto$ & $0.52(0.33,0.81)$ \\
\hline Medication & & & \\
\hline History ofmedication & $158 / 446$ & & $0.64(0.42,0.97)$ \\
\hline No history of medication & $47 / 152$ & & $0.46(0.21,1.03)$ \\
\hline & 0.05 & 0.200 .50 & 3.00 \\
\hline
\end{tabular}

\section{Figure 1}

Adjusted ORs for Mn-TWA levels associated with high TG risk in subgroups Logistic regression models was used for analysis, with high TG as the dependent variable and Mn-TWA levels (categorical variable) as the independent variable. We set subgroups according to gender, seniority, smoking status, pack years, drinking status, hypertension, medicine intake in the past two weeks, and BMI. Seniority was divided into two groups by median, and other variables were adjusted. When participants were male, or current smoker, or smoking $\geq 18$ pack-years, seniority $<18.92$ years, or non-hypertension, or high-fat diets frequency less than 3 times per week, or BMl $<24 \mathrm{~kg} / \mathrm{m} 2$, Mn-TWA levels showed negative associations with high TG risk. 